\title{
EFFECT OF PINE AND BAGASSE BIOCHAR ON PHYSICAL PROPERTIES OF SOIL
}

\author{
Isha Sharma* $^{1}$, Akshat Uniyal ${ }^{2}$ \\ ${ }^{1}$ Department of Botany, Government Autonomous Post Graduate College, Rishikesh - 249201 (Uttarakhand), India. \\ ${ }^{2}$ Laboratory of Microbiology, Department of Botany \& Microbiology, H.N.B. Garhwal University, Srinagar (G) Uttarakand-246174, India.
}

Received-May 01, 2019; Revision-May 28, 2019; Accepted-June 05, 2019

Available Online - October 15, 2019

DOI: http://dx.doi.org/10.18006/2019.7(5).423.428

KEYWORDS
Biochar
Bagasse
Pine
Pyrolysis
Physical properties of soil
C sequestration

* Corresponding author

E-mail: ishabhardwaj13@gmail.com (Isha Sharma)

Peer review under responsibility of Journal of Experimental Biology and Agricultural Sciences.

Production and Hosting by Horizon Publisher India [HPI] (http://www.horizonpublisherindia.in/).

All rights reserved.

\begin{abstract}
Biochar is the by-product of pyrolysis that has been produced for the amendment of soil profile as well as soil biota. At present waste is generated in agriculture, forests and related agro-industries is in tremendous amount. Biochar could provide a key solution by converting these wastes (biomass) into biochar for soil amendment. Biochar is a paradigm shift from chemical view to biological insight into fertility and soil food web which in-turn depends on soil physical properties. Present study was conducted to investigate the effect of pine and bagasse biochar samples on physical properties of soil. After application of these two biochar, soil samples were analyzed for moisture content, BD and WHC of soil. The data were analyzed by applying Tukey HSD test of post hoc treatment in SPSS 16.00 software. Results of study clearly signify the importance of bagasse biochar and it was followed by the pine biochar, both biochar greatly improves the physical properties of soil.
\end{abstract}

All the articles published by Journal of Experimental Biology and Agricultural Sciences are licensed under a Creative Commons Attribution-NonCommercial 4.0 International License Based on a work at www.jebas.org.

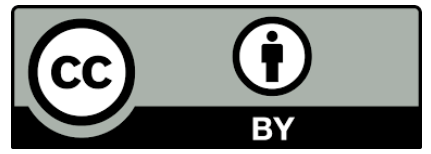




\section{Introduction}

Fertility of soil is the nation most important assets. In the present century the trend of agriculture has shifted from mixed cropping and crop rotation to the addition of chemical fertilizers that may compensate the decrease in fertility but may not affect the physical properties of soil much. Soil functions mainly depend on three prominent properties viz., physical, chemical and biological (Sassenrath et al., 2018). According to the recent research, the application of carbonization products may effectively enhance the physico-chemical characteristics of soils and improve the fertility of poor soils (Saletnik et al., 2019). Soil health is the foundation of a vigorous and sustainable food system. The continuous farming in agriculture disturbs the natural soil system including nutrient cycling along with the release and uptake of nutrients (Bot \& Benites, 2005). Plants obtain their nutrition from organic matter and mineral found in soil. Due to the increased use of chemical fertilizers and highly inefficient use of water, increases the non-profit pollution in agricultural areas around the world (EPA, 2005). With the world's population set to increase by $65 \%$ (i.e., 3.7 billion people) by 2050 , the additional food required to feed future generation will put further pressure on natural soil system and in-turn agriculture. To rectify the issues of chemical fertilizers and inefficient water uses, the biochar could be use as an alternative to enhance the soil properties. The focus of past studies was limited to nutritional status of treated soil whereas biochar is widely considered as a soil conditioner. Biochar showed positive effects on nutritional status of soil and Csequestration (Glaser et al., 2002), microbial community or soil biota (Lehmann et al., 2011) and GHG emissions (Lehmann et al., 2006; Fowles, 2007; Lehmann, 2007) which are directly or indirectly related to physical properties of soil (Berglund \& Berglund, 2011). There is little published information available about the relation between biochar treatments and physical properties of soil (Hammes \& Schmidt, 2009; Atkinson et al., 2010).

Clearly there is a knowledge gap in understanding how biochar alters physical properties of soil and the mechanism responsible for GHG emission. Thus, this work aims to study the effect of pinus and bagasse biochar on the physical properties of soil. Biochar, the solid product formed by the heating of biomass (Plant/Animal material) in an oxygen deficient environment and this is known as pyrolysis. Pyrolysis is the clean waste management process to convert biomass to solid (biochar), liquid (bio-oil) and gas. Biochar, the solid product of biomass carbonization intended as a soil amendment, has attracted attention due to its ability for long term improvements in soil physical and chemical properties with potentially important effects on soil biota. Biochar offers multitude of benefits in terms of agronomical and environmental management. The waste generated in agriculture, forests and related agro-industries has the potential to supply feedstock for biochar production.
Understanding the action of biochar is a paradigm shift from chemical views to biological insight into fertility and soil food web which in-turn depends on soil physical properties (Marjenah et al., 2016). The application of carbonized organic wastes to soil improves the physical properties of soil, soil fertility and nutrient retention (Sombroek et al., 1993; Lehmann \& Rondon, 2005; Tagoe et al., 2008). On the basis of recommendations from recent review studies (Verheijen et al., 2010; Sohi et al., 2010; Atkinson et al., 2010; Jeffery et al., 2011; Kookana et al., 2011; Barrow, 2012; Xu et al., 2012; Gurwick et al., 2013; Liu et al., 2013; Huang et al., 2013; Biederman \& Harpole, 2013; Ameloot et al., 2013; Verheijen et al., 2014), it is quite evident that effects of biochar feedstock and production process (pyrolysis conditions) on the physical, chemical and biological properties of soil must be better understood to devise effective management strategies for achieving agricultural benefit.

\section{Materials and Methods}

\subsection{Feedstock Selection}

The feedstocks used in present investigation are pine needles and sugarcane derived bagasse (SCB). The pine needles were collected from different forest areas of Dehradun and bagasse was collected from sugar mill company limited Doiwala, Dehradun. The feedstock was air dried for 24 hours and then crushed into small pieces.

\subsection{Biochar Production}

Slow pyrolysis is the most common referred method for biochar production (Yadav \& Jagadevan, 2019). Feedstock is the most important factor that controls the properties of resulting biochar. Ligno-cellulosic feedstocks with high content of alkalines ( $\mathrm{Na}, \mathrm{K}$, $\mathrm{Mg}$ and $\mathrm{Ca}$ ) resulted higher yields of biochar and relatively low yields of quality bio-oil. Feedstock rich in cellulose produced rich pyrolytic sugars, low molecular weight organic acids and water; whereas feedstock high in lignin produced high energy bio-oils enriched with mono and oligo phenols. The feedstock was pyrolysed at $500^{\circ} \mathrm{C}$ under the recommendation of Lehmann (2007). The pine needles were pyrolysed for 20 minutes and bagasse was pyrolysed for 30 minutes. After the biochar was taken out from muffle furnace the biochar was allowed to cool. This biochar was crushed with mortar and pestle and sieved with $4 \mathrm{~mm}$ mesh.

\subsection{Soil Sampling}

The soil used in the experiment was collected from Botanical garden of government P.G College Rishikesh. A composite sample was collected $10 \mathrm{~cm}$ below the top soil layer. The soil was dried for 24 hours. Prior to potting the soil was sieved through $4 \mathrm{~mm}$ mesh to remove the plant debris, stones and other unwanted material. Biochar was applied @ 10\% (w/w) according to big biochar 
experiment of IBI. Thus, in each pot $100 \mathrm{gm}$ biochar is mixed with 900gm soil and pots were kept for 4-5 months.

\subsection{Experimental Plot and Treatments}

Pot trials were conducted for the comparative study of effect of different types of biochar on the physical properties of soil. This study was carried out for two consecutive years i.e. 2014 and 2015. Study was conducted in RBD with three treatments viz., Untreated soil (Control), Pine biochar treatment (PB), Bagasse biochar treatment $(\mathrm{BB})$ with three replicates.

\subsection{Experimental Analysis}

\subsubsection{Determination of Moisture Content}

The moisture content of the soil samples was calculated as per standard method given by Mishra (1968).

$$
\text { Moisture content }(\%)=\frac{\text { Fresh weight }- \text { Dry weight }}{\text { Dry weight }} \times 100
$$

\subsubsection{Determination of $\mathrm{BD}$}

It was calculated as the dry weight of soil divided by its volume This volume includes the volume of soil particles and its pores among soil particles. It is an indicator of soil compaction.

$$
\text { Bulk density }=\frac{\mathrm{W}_{2}-\mathrm{W}_{1}}{\mathrm{~V}}
$$

Whereas, $\mathrm{W}_{2}$ = weight of bottle containing dry soil, $\mathrm{W}_{1}=$ weight of empty bottle and $\mathrm{V}=$ volume of bottle

\subsubsection{Determination of WHC of soil}

For measuring water holding capacity of soil, first of all dry watch glass + keen box + filter paper were weighed. This was followed by the filling keen box with fine grinded soil and saturated with water. The soil was allowed to absorb moisture. The excess water was removed from saturated soil and weighed again. The keen box with saturated soil was placed in oven for 24 hours to dry up and was weighed again. Collected data were calculated by following

1 Weight of dry filter papers say $\quad-0.20,0.18,0.16,0.20$ - Total weight $\quad$ - A 2. Weight of wet filter papers say $-0.40,0.48,0.48 \quad$ - Total weight $\quad$ - B 3 Average weight of water held by one filter paper $=\frac{B-A}{\text { No. of filter papers }}-\mathrm{C}$

$$
\mathrm{WHC}=\frac{(\mathrm{WSS}+\mathrm{KB}+\mathrm{FP})-(\mathrm{WODS}+\mathrm{KB}+\mathrm{AWWHFP}) \times 100}{(\mathrm{WWG}+\mathrm{KB}+\mathrm{FP})}
$$

Where WWS - Weight of saturated soil; KB - Keen box; FP - Filter Paper; WODS - Weight of oven dry soil; AWWHFP -
Average weight of water hold by one filter paper and WWG Weight of watch glass

\subsection{Statistical Analysis}

For analyzing the data obtain through experiment on effect of pine and bagasse biochar on physical properties of soil, ANOVA for one way classification was applied and the data was analyzed using SPSS software. For comparison of pine and bagasse in order to assess their performance regarding physical parameters of soil i.e., WHC, BD and moisture Tukey's HSD test was applied.

\section{Results}

The data obtained from the study of effect of two biochar on physical properties of soil were given in table 1 .

\subsection{Effect of Biochar on Bulk Density of Soil}

The data obtain from mean values revealed that biochar have reducing effect on the bulk density (BD) of soil. The $\mathrm{BD}$ of soil was reported from 0.68 (BB) to 1.32 (Control) in 2014 while it was reported from 0.67 (BB) to 1.32 (Control) in 2015, while this value was reported $0.68(\mathrm{BB})$ to 1.32 (Control) in pool analysis. Further, the $\mathrm{BD}$ for Control, $\mathrm{PB}$, and $\mathrm{BB}$ are reported 1.32, 0.89 and 0.68 respectively in 2014 while this was reported $1.32,0.88,0.67$ in 2015 and 1.32, 0.88 and 0.68 respectively in pool analysis. Both the biochar treatments (PB and $\mathrm{BB}$ ) were found to decrease BD of soil. Further, bagasse biochar was found more effective in decreasing the BD of soil as compare to pine biochar (Table 1).

\subsection{Effect of Biochar on WHC of Soil}

The water holding capacity (WHC) of soil ranges from 15.80 (Control) to 22.14 (BB) in 2014, 16.05 (Control) to 22.13 (BB) in 2015 and 15.93 (Control) to 22.14 (BB) in pool analysis. Further, results of study revealed that $\mathrm{WHC}$ for control, $\mathrm{PB}$, and $\mathrm{BB}$ was reported $15.80,18.32$ and 22.11 respectively in 2014 while this was reported $16.05,18.30,22.13$ in 2015 and 15.93, 18.28 and 22.12 respectively in pool analysis. Results of study suggested that both biochar treatments (PB and $\mathrm{BB}$ ) were effective in increasing WHC of soil for both the study years. No significant difference was reported in the data obtained for both the studied years for both the biochar while among the both tested biochar, bagasse biochar was found more effective in increasing the WHC of soil and it was significantly different from the pinus biochar (Table 1).

\subsection{Effect of Biochar on Moisture Content of Soil}

The moisture content of soil ranges from 8.37 (Control) to 33.47 (BB) in 2014 while it range from 8.27 (Control) to 33.30 (BB) in 2015 and 8.32 (Control) to 33.38 (BB) in pool analysis (Table 1). The moisture content for all soil samples are 8.37 (Control), 13.37 
Table 1 Effect of biochar incorporation on physical properties of soil.

\begin{tabular}{|cccccccccc|}
\multirow{2}{*}{ Treatments } & \multicolumn{3}{c}{2014} & \multicolumn{3}{c}{2015} & \multicolumn{3}{c|}{ Pool Analysis } \\
& WHC $(\%)$ & BD $\left.\left(\mathrm{g} / \mathrm{cm}^{3}\right)\right|^{\prime}$ & Moisture $(\%)$ & WHC $(\%)$ & BD $\left(\mathrm{g} / \mathrm{cm}^{3}\right)$ & Moisture $(\%)$ & WHC $(\%)$ & BD $\left(\mathrm{g} / \mathrm{cm}^{3}\right)$ & Moisture $(\%)$ \\
\hline Control & $15.80 \pm 0.360$ & $1.32 \pm 0.024$ & $8.37 \pm 0.230$ & $16.05 \pm 0.185$ & $1.32 \pm 0.025$ & $8.27 \pm 0.208$ & $15.93 \pm 0.27$ & $1.32 \pm 0.025$ & $8.32 \pm 0.175$ \\
\hline PB & $18.32 \pm 0.011$ & $0.89 \pm 0.011$ & $13.37 \pm 0.058$ & $18.32 \pm 0.025$ & $0.88 \pm 0.153$ & $13.03 \pm 0.152$ & $18.32 \pm 0.006$ & $0.88 \pm 0.018$ & $13.20 \pm 0.1$ \\
\hline BB & $22.14 \pm 0.040$ & $0.68 \pm 0.002$ & $33.47 \pm 0.152$ & $22.13 \pm 0.025$ & $0.67 \pm 0.007$ & $33.30 \pm 0.264$ & $22.14 \pm 0.029$ & $0.68 \pm 0.003$ & $33.38 \pm 0.202$ \\
\hline
\end{tabular}

CONTROL - Untreated soil ; PB - Pine biochar treatment; BB - Bagasse biochar treatment.

Table 2 Effect of biochar incorporation on physical properties of soil leveled by Tukey's HSD test of post-hoc treatment.

\begin{tabular}{|ccccccccccc|}
\hline & \multicolumn{3}{c}{2014} & & \multicolumn{3}{c}{2015} & \multicolumn{3}{c|}{ Pool Analysis } \\
Treatments & WHC $(\%)$ & BD $\left(\mathrm{g} / \mathrm{cm}^{3}\right)$ & Moisture (\%) & WHC $(\%)$ & BD $\left(\mathrm{g} / \mathrm{cm}^{3}\right)$ & Moisture (\%) & WHC $(\%)$ & BD $\left(\mathrm{g} / \mathrm{cm}^{3}\right)$ & Moisture $(\%)$ \\
\hline Control & $15.80^{\mathrm{a}}$ & $1.32^{\mathrm{c}}$ & $8.37^{\mathrm{a}}$ & $16.05^{\mathrm{a}}$ & $1.32^{\mathrm{c}}$ & $8.27^{\mathrm{a}}$ & $15.93^{\mathrm{a}}$ & $1.32^{\mathrm{c}}$ & $8.32^{\mathrm{a}}$ \\
\hline PB & $18.32^{\mathrm{b}}$ & $0.89^{\mathrm{b}}$ & $13.37^{\mathrm{b}}$ & $18.32^{\mathrm{b}}$ & $0.88^{\mathrm{b}}$ & $13.03^{\mathrm{b}}$ & $18.32^{\mathrm{b}}$ & $0.88^{\mathrm{b}}$ & $13.20^{\mathrm{b}}$ \\
\hline BB & $22.14^{\mathrm{c}}$ & $0.68^{\mathrm{a}}$ & $33.47^{\mathrm{c}}$ & $22.13^{\mathrm{c}}$ & $0.67^{\mathrm{a}}$ & $33.30^{\mathrm{c}}$ & $22.14^{\mathrm{c}}$ & $0.68^{\mathrm{a}}$ & $33.38^{\mathrm{c}}$ \\
\hline
\end{tabular}

$(\mathrm{PB})$ and $33.47(\mathrm{BB})$ in 2014 , whereas in it was recorded as 8.27 (Control), 13.03 (PB), $33.30(\mathrm{BB})$ respectively in 2015 and 8.32 (Control), 13.20 (PB) and 33.38 (BB) in pool analysis. Like WHC, biochar amended soil have higher moisture content and bagasse biochar was found significantly different that the all tested treatments.

\subsection{Statistical Analysis of Data}

The results of biochar incorporation on physical parameter of soil leveled by tukey's HSD test of post hoc treatment are given in table 2. Analysis of data suggested the significant effect of biochar on the physical properties of soil and among the tested biochar, bagasse biochar was found significantly different that the other treatments.

\section{Discussion}

From the perusal of results it was reported that biochar application statistically increases WHC and moisture content. The bagasse biochar treatment was found statistically superior than pine treatment. It was also clear from the study that biochar treatment decreases BD and it has been found that lower BD increases the soil aeration and better in the movement of water and ions. Further, bagasse treatment is found to decrease BD more than pine treatment however WHC and Moisture follows the same trend. These findings are in line with the findings of $\mathrm{Yu}$ et al. (2013), Laird et al. (2010), Jones et al. (2010) and Chen et al. (2011). The highest WHC and moisture content has been found in bagasse biochar due to its high porosity than pine biochar. Sohi et al. (2009) showed that soil with a high WHC increases crop yields and decreases irrigation needs. Soil hydrological properties (WHC and Moisture content) are directly related to surface area, porosity, $\mathrm{BD}$ and aggregate stability. The decrease in $\mathrm{BD}$ in biochar treated soil is one of the most important indicator of enhancement in soil structure. Biochar application increases the water retention capacity of soil as it increases soil porosity and due to adsorptive nature of biochar (Herath et al., 2013). In general, it can be concluded that biochar amendment to soil increase the porosity, availability of water, nutrient retention capacity and decreased the soil BD (Lei \& Zhang, 2013). However Dume et al. (2016) reported that biochar cannot change the texture of soil, this is also in agreement with the findings of present study.

\section{Conclusion}

The achieved results of current investigation has shown that bagasse biochar is more suitable for improving soil physical properties and suggesting it superior than pine biochar. No doubt crop yield depend on the functioning of standard soil i.e. the yield of a crop depends on both the physical and chemical properties of soil. The chemical properties of soil or ions alone can't do anything until physical properties will improve. If WHC, moisture content of soil and movement of water soluble ion is better then only the chemical ions from biochar will pass to the soil and enhance its chemical status. The biochar is more stable than compost and livestock manure as it has higher capacity to hold nutrients. Thus, this development mechanism can be adopted to achieve the goal of maintaining the fertility of soil in urbanization as it is cost effective and environment friendly practice which is the need of hour in this world of science and technology. 


\section{Conflict of Interest}

Author hereby declare no conflict of interest

\section{References}

Ameloot N, Graber ER, Verheijen FGA, Neve D (2013) Interactions between biochar stability and soil organisms: review and research needs. European Journal of Soil Science 64: 379-390.

Atkinson CJ, Fitzgerald JD, Hipps NA (2010) Potential mechanisms for achieving agricultural benefits from biochar application to temperate soils: A review. Plant and Soil 337: 1-18.

Barrow CJ (2012) Biochar: Potential for countering land degradation and for improving agriculture. Applied Geography 34: 21-28.

Berglund O, Berglund K (2011) Influence of water table level and soil properties on emissions of greenhouse gases from cultivated peat soil. Soil Biology and Biochemistry 43: 923-931.

Biederman LA, Harpole WS (2013) Biochar and its effects on plant productivity and nutrient cycling: a meta-analysis. Bioenergy 202-214.

Bot A, Benites J (2005) The Importance of Soil Organic Matter: Key to Drought-Resistant Soil and Sustained Food Production, FAO UN: Rome, Italy.

Chen HX, Du ZL, Guo W, Zhang QZ (2011) Effects of biochar amendment on cropland soil bulk density, cation exchange capacity, and particulate organic matter content in the North China plain. Chinese Journal of Applied Ecology 22: 29- 34.

Dume B, Mosissa T, Nebiyu A (2016) Effect of biochar on soil properties and lead $(\mathrm{Pb})$ availability in a military camp in South West Ethiopia. African Journal of Environmental Science and Technology 10: 77-85.

EPA (2005) Protecting Water Quality from Agricultural Runoff U.S. Environmental Protection Agency, Washington, DC 2005.

Fowles M (2007) Black carbon sequestration as an alternative to bioenergy. Biomass and Bioenergy 31: 426-432.

Glaser B, Lehmann J, Zech W (2002) Ameliorating physical and chemical properties of highly weathered soils in the tropics with charcoal-A review. Biology and Fertility of Soils 35: 219-230.

Gurwick NP, Moore LA, Kelly C, Elias P (2013) A systematic review of biochar research, with a focus on its stability and its promise as a climate mitigation strategy. Plos One 8: 75932.

Hammes K, Schmidt M (2009) Changes in Biochar in Soil. In: Biochar for Environmental Management: Science and Technology, London
Herath HMSK, Camps-Arbestain MC, Hedley M (2013) Effect of biochar on soil physical properties in two contrasting soils: an alfisol and an andisol. Geoderma 209: 188-197.

Huang M, Yang L, Qin H, Jiang L, Zou Y (2013) Quantifying the effect of biochar amendment on soil quality and crop productivity in Chinese rice paddies. Field Crops Research 154: 172-177.

Jeffery S, Verheijen FGA, van der Velde M, Bastos AC (2011) A quantitative review of the effects of biochar application to soils on crop productivity using meta-analysis. Agriculture Ecosystem and Environment 144: 175-187.

Jones BEH, Haynes RJ, Phillips IR (2010) Effect of amendment of bauxite processing sand with organic materials on its chemical, physical and microbial properties. Journal of Environmental Management 91: 2281-2288.

Kookana RS, Sarmah AK, Van Zwieten L, Krull E, Singh B (2011) Biochar application to soil: Agronomic and environmental benefits and unintended consequences. Advance Agrononomy 112: $103-143$

Laird DA, Fleming P, Davis DD, Horton R, Wang BQ, Karlen DL (2010) Impact of biochar amendments on the quality of a typical mid western agricultural soil. Geoderma 158: 443-449.

Lehmann J (2007) Bio-energy in the black. Frontiers in Ecology and Environment 5: 381-387.

Lehmann J, Rondon M (2005) Bio-char soil management on highly weathered soils in the humid tropics In: Biological Approaches to Sustainable Soil Systems, Boca Raton, CRC Press.

Lehmann J, Gaunt J, Rondon M (2006) Bio-char sequestration in terrestrial ecosystems: a review. Mitigation and Adaptation Strategies for Global Change 11: 403-427.

Lehmann J, Rillig M.C, Thies J, Masiello CA, Hockaday WC, Crowley D (2011) Biochar effects on soil biota-A review. Soil Biology and Biochemistry 43: 1812-1836.

Lei O, Zhang R (2013) Effects of biochars derived from different feedstocks and pyrolysis temperatures on soil physical and hydraulic properties. Journal of Soils Sediments 13: 1561-1572.

Liu X, Zhang A, Ji C, Joseph S, Bian R, Li L, Pan G, Pan-Ferreiro J (2013) Biochar's effect on crop productivity and the dependence on experimental conditions-A meta analysis of literature data. Plant and Soil 373:583-594.

Marjenah, Kiswanto, Purwanti S, Sofyan FPM (2016) The effect of biochar, cocopeat and saw dust compost on the growth of two dipterocarps seedlings. Nusantara Bioscience 8(1): 39-44.27. 
Mishra R (1968) Ecology work book. Oxford and I.B.H. Tagoe SO, Horiuchi T, Matsui T (2008) Effects of carbonized and Publication, Co. New Delhi.

Saletnik B, Zaguła G, Bajcar M, Tarapatskyy M, Bobula G, Puchalski C (2019) Biochar as a Multifunctional Component of the Environment-A Review. Applied Science (9) 1139. doi:10.3390/app9061139. dried chicken manures on the growth, yield and $\mathrm{N}$ content of soybean. Plant and Soil 306:211-220.

Verheijen F, Jeffery S, Bastos AC, van der Velde M, Diafas I (2010) Biochar application to soils. A critical scientific review of effects on soil properties, processes, and functions. EUR 24099 EN, Office for the Official Publications of the European Communities, Luxembourg.

Sassenrath GF, Davis K, Sassenrath-Cole A, Riding N (2018) Exploring the Physical, Chemical and Biological Components of Soil: Improving Soil Health for Better Productive Capacity. Kansas Agricultural Experiment Station Research Reports: Vol. 4: Iss. 3. https://doi.org/10.4148/2378-5977.7577.

Sohi S, Krull E, Lopez-Capel E, Bol R (2010) A review of Biochar and its use and function in soil. Advances in Agronomy 105: 47-79.

Sohi S, Lopez-Capel E, Krull E, Bol R (2009) Biochar, climate change and soil: A Review to Guide Future Research. In: CSIRO Land and Water Science Report Series.

Sombroek W, Nachtergaele FO, Hebel A (1993) Amounts, dynamics and sequestering of carbon in tropical and subtropical soils. Ambio 22: 517-426.

Verheijen FGA, Graber ER, Ameloot N, Bastos AC, Sohi S, Knicker H (2014) Biochars in soils: New insights and emerging research needs. European Journal of soil Science 65: 22-27.

Xu G, Lv Y, Sun J, Shao H and Wei L (2012) Recent advances in biochar applications in agricultural soils: Benefits and environmental implications. Clean-Soil, Air, Water 40:1093-1098.

Yadav K, Jagadevan S (2019) Influence of Process Parameters on Synthesis of Biochar by Pyrolysis of Biomass: An Alternative Source of Energy DOI: http://dx.doi.org/10.5772/intechopen.88204.

Yu OY, Raichle B, Sink S (2013) Impact of biochar on the water holding capacity of loamy sand soil. International Journal of Energy and Environmental Engineering 4:44.

Journal of Experimental Biology and Agricultural Sciences http://www.jebas.org 